\title{
PROYECTO DE ACOMPAÑAMIENTO CULTURAL PARA NIÑOS: ENCUENTROS EN GALERÍAS DE ARTE
}

\author{
Recepción: 22/02/2019 | Revisión: 25/03/2019 | Aceptación: 03/06/2019
}

\author{
María José LOBATO SUERO \\ Cardenal Spínola. Fundación San \\ Pablo Andalucía CEU \\ mjlobato@ceuandalucia.es
}

\author{
Carmen SALAZAR-PERA \\ Cardenal Spínola. Fundación San Pablo Andalucía CEU \\ Facultad de Bellas Artes. Universidad de Sevilla \\ msalazar@us.es
}

\begin{abstract}
Resumen: En este artículo se describe una acción educativa no formal -acompañamiento cultural- con la que se pretende contribuir a la aproximación a la cultura visual de la infancia y facilitar el sentimiento de pertenencia a lugares de difusión de experiencias artísticas del entorno cercano, favoreciendo así el enriquecimiento personal de las familias y la formación de estudiantes universitarios en el marco del aprendizaje-servicio (ApS).

El proyecto se desarrolla en galerías y centros de arte que no disponen de gabinete pedagógico, atención específica, ni acciones educativas para niños, niñas y familias en general. Se vincula a un proyecto de investigación-colaboración llevado a cabo por profesores universitarios en coordinación con becarios-estudiantes universitarios del Centro Cardenal Spínola de la Fundación San Pablo Andalucía CEU de los Grados de Educación Infantil y/o Primaria.

Desde el punto de vista metodológico, en el proyecto se aborda una investigación tanto cualitativa como cuantitativa. En el análisis de los datos aportados en cada encuentro, se contemplan aspectos como la respuesta o afluencia a la convocatoria, los medios para realizar la llamada, el grado de satisfacción para cada grupo de participantes, etc. Las apreciaciones cualitativas también revelarán datos sobre el grado de aceptación del proyecto por las familias y galerías.
\end{abstract}

Palabras clave: galerías de arte; acción educativa no formal; acompañamiento a niños; conquista de espacios; sentimiento de pertenencia.

\section{PROJECT OF CULTURAL ACCOMPANIMENT FOR CHILDREN: MEETINGS IN ART GALLERIES}

Abstract: This article describes a non-formal educational action-cultural accompaniment- with which it is intended to contribute to the approach to visual culture in childhood, and to facilitate the feeling of belonging to places of dissemination of artistic experiences from one's surroundings, thus favoring the personal enrichment of families and the training of university students in the framework of service-learning (SL). \The project was developed in galleries and art centers that do not have a pedagogical office, specific attention, or educational actions for children and families in general. It is linked to a researchcollaboration project carried out by university lecturers in coordination with scholarship-students from Cardenal Spinola Centre of the Fundación San Pablo Andalucía CEU in the degrees of Early Years and/or Primary Education. From a methodological point of view, both qualitative and quantitative research is addressed in this project. In the analysis of the data provided in each meeting, aspects such as the response or attendance, the means to make the call, the degree of satisfaction of each group of participants, etc. are contemplated. The qualitative assessments also reveal data on the degree of acceptance of the project by families and galleries.

Keywords: art galleries; non-formal educational action; accompanying children; conquest of spaces; sense of belonging.
PROJECTE D'ACOMPANYAMENT CULTURAL PER A NENS:TROBADES EN GALERIES D'ART

Resum: En aquest article es descriu una acció educativa no formal -acompanyament cultural- amb la que es pretén contribuir a l'aproximació a la cultura visual de la infáncia $i$ facilitar el sentiment de pertinença a llocs de difusió d'experiències artístiques de l'entorn pròxim, afavorint d'aquesta manera l'enriquiment personal de les famílies $i$ la formació d'estudiants universitaris en el marc de l'aprenentatge-servei (ApS). El projecte es desenvolupa en galeries $i$ centres d'art que no disposen de gabinet pedagògic, atenció específica, ni accions educatives per a nens, nenes $i$ famílies en general. Es vincula a un projecte d'investigació-col-laboració conduit per professors universitaris en coordinació amb becaris-estudiants universitaris del Centre Cardenal Spinola de la Fundación San Pablo Andalucía CEU dels Graus d'Educació Infantil i/o Primària. Des del punt de vista metodologic, en el projecte s'aborda una investigació tant qualitativa com quantitativa. En l'anàlisi de les dades aportades en cada trobada es contemplen aspectes com la resposta o afluència a la convocatòria, els mitjans per realitzar la crida, el grau de satisfacció per a cada grup de participants, etc. Les apreciacions qualitatives també revelaran dades sobre el grau d'acceptació del projecte per les famílies i galeries.

Paraules clau: galeries d'art; acció educativa no formal; acompanyament a nens; conquesta d'espais; sentiment de pertinença. 


\section{Introducción}

La acción educativa no formal descrita se desarrolla en el contexto referido por Martínez (2008) Aprendizaje servicio y responsabilidad social en las universidades. El proyecto responde a la falta de atención a la infancia en determinados aspectos de la cultura visual, y persigue crear líneas de acompañamiento, tendiendo lazos entre la producción cultural contemporánea, la actividad expositiva, la acción social y la docencia-investigación.

En primer lugar, se desarrolla una fase de fundamentación teórica (noviembre-marzo de 2018) y una experiencia piloto (abril de 2018). Se cierra la segunda fase, durante el curso 2018 2019, en la que se realiza la implantación de seis acompañamientos. En la actualidad se empieza una fase de consolidación de la experiencia, verificación/medición de los resultados y reflexión sobre su calado y alcance.

El proyecto Acompañamiento a niños en galerías de arte está coordinado por profesores del centro universitario Cardenal Spínola de las Áreas departamentales de Pedagogía y Educación Plástica-visual y se vincula a las becas de la Fundación San Pablo Andalucía CEU de Sevilla (en adelante CEU Sevilla) para los Grados de Educación. También se invita a alumnos internos que desean mejorar su formación, respondiendo así al interés de estudiantes que no cumplen los re-quisitos para ser becados. Se puntualiza que el proyecto no pretende fines comerciales. El propósito es una acción social de colaboración para subvertir ciertas situaciones, aportando nue-vas vías para el acercamiento familiar, a través del arte contemporáneo; promover la formación de futuros maestros y aportar datos a la investigación sobre la influencia que la acción reporta a las familias y a las galerías de arte.

La acción de acompañamiento se desarrolla en galerías de arte (Lobato y Salazar, 2017) que no disponen de gabinete pedagógico o atención pedagógica específica a la infancia (niños y niñas de Educación Infantil y Primaria).

Esta actividad está orientada a los encuentros con el arte y basada en observaciones previas que alertan sobre la evidente discrepancia existente entre la ingente presencia de actividades e invitación a la infancia en los museos, con respecto a la misma circunstancia en las galerías de arte.

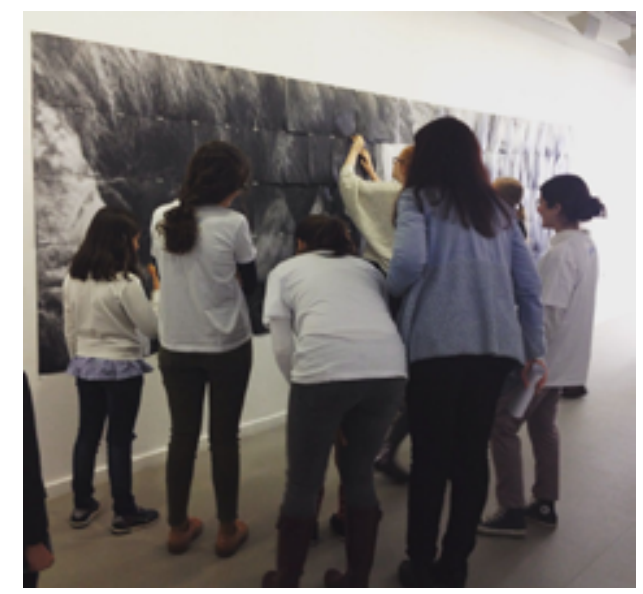

Figura 1. Niños, becarios y coordinadores del encuentro (profesorado universitario y galeristas), 2018.

(Galería Alarcón-Criado, Sevilla). Fuente: propia. 


\section{Fundamentación: lugares de encuentro. Museo vs. galería}

$\mathrm{El}$ acercamiento a lugares de arte aporta, en concreto para niños y niñas, una serie de beneficios que se hacen extensivos al contexto próximo, tales como el potencial de enriquecimiento personal, la desconexión de la rutina, las sensaciones anímicas positivas, la experimentación de novedades y la vivencia de experiencias lúdicas. En estas actividades, niños, niñas y adultos, podrían convertirse en motor de cambio, al mejorar roles sociales y activar la presencia cultural en el entorno familiar. (Calaf y Fontal, 2004; Laboratorio Permanente de Museos, 2012; Moreno, 2016)

Borja-Villel (2018:3), en su calidad de director del Museo Reina Sofía, alude a que los "museos son lugares que, dependiendo de cómo los habitemos y concibamos, se sitúan lejos o cerca de nosotros/as". Estas visitas pueden tener un papel relevante en el conocimiento de relaciones, vínculos sociales o historias familiares más amplias para los participantes.

De hecho, desde Bordieu (1983), los términos "capital social" y "capital cultural" se refieren al bagaje cultural y la interacción social, bienes intangibles recibidos por relaciones o pertenencia a grupos familiares y sociales determinados, en los que construir un imaginario propio (Gómez y Vaquero-Cañestro, 2014). No es de extrañar el relevante incremento que ha experimentado el número de visitantes a museos y colecciones museográficas de arte contemporáneo. Sin embargo, en un momento en que la obra de arte ha salido del espacio privado y se hace pública (Benjamin, 2003), la aproximación a la cultura visual modifica la percepción de los espacios expositivos como lugares elitistas.

El inspirador texto de Borja-Villel apoya la necesidad de propiciar encuentros: los centros de arte pueden constituirse en "agentes generadores de vínculos y espacios inestables en los que las ideas de dentro y fuera se entrecruzan y redefinen continuamente". Es de vital importancia establecer un marco flexible que permita "a cada visitante a descubrir cómo quiere relacionarse" en ese "espacio social compartido" (cf. Borja-Villel, 2018:4).

Beaumont y Sterry, especialmente, aluden en un estudio sobre abuelos y nietos en museos y galerías, a que los visitantes de una exposición determinada se centran más en ella, pasan más tiempo en su contemplación y experimentan una mejor retroalimentación que si lo hacen en museos o grandes exposiciones; del mismo modo, aumenta la duración de la visita si la realizan acompañados por alguien que se sienta emotivamente vinculado al lugar o a la temática por algún motivo externo a la exposición pero propio del visitante (Beaumont y Sterry, 2005; Calaf y Fontal, 2004).

Resaltamos el hecho de que ambos espacios - museos y galerías de arte- manifiestan discrepancias en origen y objetivos; así, nos cuestionamos el paralelismo existente. Las galerías de arte parten de planteamientos comerciales y en el espacio museístico no se pretende tal finalidad. En algunos de los estudios revisados se analiza, de forma indistinta, la asistencia a museos y galerías de un colectivo muy determinado. En él se engloba a la infancia y la edad adulta y se establecen factores que afectan a sus vivencias, relaciones con su infancia, motivaciones específicas por relación previa con el museo o galería, condición física o distancia de desplazamientos, etc. No se desdeñan tampoco otros factores que inciden sobre la tipología de las relaciones entre los sujetos y la calidad de la convivencia de ambos en el marco de la actividad, desplazándose el estudio hacia 
aspectos cualitativos. (Beaumont y Sterry, 2005)

Abundan en los museos las referencias de proyectos orientados a los niveles escolares; pero se carece de referencias sobre actividades en el entorno de galerías de arte (Lobato y Salazar, 2017). En el panorama español solo nos constan visitas guiadas, talleres, etc. en la Galería Espacio Mínimo de Madrid, Arteko en San Sebastián y Aleph en Ciudad Real (Sánchez-Pacheco, 2011).

Siguiendo el rastro de las webs de las galerías, y hasta donde hemos podido conocer, solo la APPA art gallery (Madrid) que inicia su actividad en 2016, indica de forma expresa en su declaración legal que sus imágenes y documentos "pueden ser utilizados con fines educativos y personales", y realiza colaboraciones con colegios, pero sin un proyecto específico. PLOM Gallery, una galería de arte para niños que abre en 2013 en Barcelona, expone y vende obras para estimular la creatividad y la imaginación, y enseñar a apreciar el valor de una obra artística. Según el estudio de Ortega y Pardo (2017) sí se tiene la certeza de iniciativas didácticas en galerías de Gran Bretaña y Alemania.

La relación estudiantes-museo, estudiantes-galerías de arte, en el marco del ApS universitario español, tampoco es fácil de rastrear. Sí constan proyectos en centros de secundaria (Nuestros nietos de la ESO nos llevan al Museo Arqueológico Nacional); "Voluntarios Culturales de la tercera edad para enseñar los Museos de España a niños, jóvenes y jubilados", ONG que colabora con el MAN; el Plan de voluntariado del Centro de Cultura Tradicional Museo Escolar de Pusol; la Federación Española de Amigos de los Museos, etc. Sin embargo, sentaron las bases tempranas experiencias a través de distintos agentes sociales: en 1921 en el Antioch College (Ohio), e inspirado en Dewey, se funda un programa de servicio comunitario estudiantil, probablemente el más antiguo de Estados Unidos, pionero del aprendizaje servicio. En México, en el Servicio Social (c. 1945), se dan las primeras experiencias universitarias de servicio comunitario estudiantil. Paradójicamente, el término "aprendizaje servicio" (SL, service-learning), con origen en proyectos de desarrollo local estudiantiles de Tennessee en 1967 (Martínez, 2008), todavía resulta una práctica innovadora. La filosofía del ApS es aprender haciendo para solucionar problemas o circunstancias reales.

\section{Descripción de la actividad: acompañar en las galerías}

Esta actividad tiene su origen en vincular la acción social de las becas de colaboración de CEU Sevilla y el aprendizaje-servicio integrando programas del ámbito de la Educación Superior (Zorrilla, 2016) con la formación de los futuros maestros.

Los agentes pasivos son niños y niñas del segmento de Educación Infantil y Primaria (Huerta y De la Calle, 2007) junto con sus familias, las galerías de arte y sus directores. Los agentes activos son los estudiantes de Grado de Infantil y Primaria (colaboradores becarios y alumnos internos), y el profesorado que coordina el proyecto. El interés por reunir en el acompañamiento al público infantil y los estudiantes, se determina por constituir un eje vertebrador de la formación cultural visual y plástica. Los estudiantes de Grado de hoy serán futuros maestros de Infantil y Primaria; y es en estas etapas en las que se concretan las preferencias básicas de la persona y se crean rutinas de ocio y aprendizaje lúdico. 


\section{Objetivos: el reto}

En tanto que los beneficiarios del proyecto (Lobato y Salazar, 2017) son niños y niñas, familias (adultos), becarios y galerías, los objetivos inciden en aspectos culturales o de la educación no formal que contribuyen a la mejora del entorno social de las personas.

La escasez de hallazgos sobre experiencias similares en el contexto español ha sido determinante para animar el proyecto; sin embargo, las referencias de diferentes contextos, motivaciones, resultados, etc., habrían contribuido a la puesta en marcha, la elaboración previa de los objetivos y las acciones. Con respecto a otros proyectos similares conocidos, encontramos puntos diferenciadores: el lugar predominante de otras intervenciones es el museo, los destinatarios son otros, el contexto es diferente, etc. (Moreno, 2016).

Se puede determinar una hipótesis o macro-objetivo que engloba a todos los interesados: el proyecto persigue crear sinergias entre familias y galerías, determinando las pautas necesarias para llevar a cabo una labor social y proyecto cultural encaminado a la conquista progresiva de este espacio de arte (Alsina y Giráldez, 2012; Beaumont y Sterry, 2005; San Millán y Barrenetxea, 2012).

Se desglosa el objetivo dependiendo de aquellos grupos a los que afecta:

- En niños y niñas: desarrollar habilidades comunicativas y enriquecer su imaginario y bagaje cultural. (El proyecto vincula a la propuesta los objetivos de la legislación, tanto de Educación Infantil como de Primaria.)

- En niños, niñas y adultos: encontrarse de manera lúdica y no formal con el patrimonio contemporáneo. Se focaliza en cómo promover la desmitificación, la dimensión cotidiana de la cultura. (Calaf y Fontal, 2004:86; Fontal, Marín y García, 2015:38).

- En las familias: generar iniciativa y autonomía para este tipo de actividades, y articular relaciones para la conquista de escenarios de encuentros con la cultura artística.

- En los estudiantes universitarios (becarios): definir el puente de unión entre lo académico, la prestación de servicios y la acción social, constatar la aportación a su formación, e incitarlos a llevar a cabo servicios a la comunidad que reviertan en cambios significativos en la concepción del papel de las artes en la sociedad (Lobato y Salazar, 2017).

- En relación las galerías: dar visibilidad de sus posibilidades en la difusión de la cultura visual y establecer el marco de acogida a las familias.

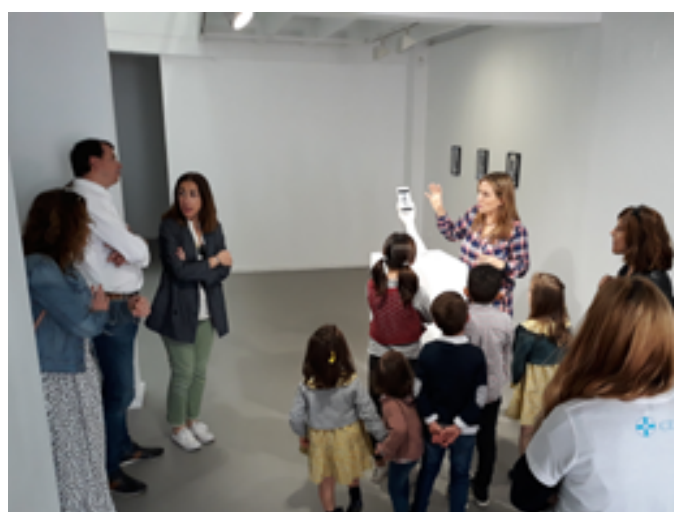

Figura 2. Presentación del encuentro por la galerista, 2019. (Galería Alarcón-Criado, Sevilla). Fuente: propia. 


\section{Metodología y muestreo}

Partiendo de la idea de que el proyecto tiene un desarrollo teórico-práctico y se retroalimenta constantemente, hay una intención de establecer un marco de acompañamiento flexible. En alusión a Muntadas (2019) el proyecto puede considerarse como un work-in-progress ya que procedimientos y maneras de trabajar dependen de la búsqueda de estructuras apropiadas y enfocadas a su comprensión. La exploración es parte integrante del trabajo, vinculándose de forma indisociable al contexto que lo genera.

Desde un punto de vista cronológico, el proyecto depende del calendario académico de grado, de octubre a abril-mayo (a expensas de festividades, exámenes, etc.). En el curso 2017-2018 se forma un equipo con tres alumnas: una becaria de colaboración y dos alumnas internas, y el profesorado del área de Pedagogía y Expresión Plástica. Se sistematizan unos objetivos para la aproximación al marco teórico y la puesta en marcha.

En la toma contacto con las galerías de la ciudad, se seleccionan nueve, que pertenecen a la asociación de Galerías de arte Sevilla (en adelante AGAS). La mayoría se encuentran situadas en un radio de unos 800 metros en el centro metropolitano, solo dos de ellas distan aproximadamente 1 y $1.5 \mathrm{~km}$. Se han realizado siete acompañamientos, exceptuando la experiencia piloto de 2017 que sigue:

El marco muestral tomó cualquier tipo de unidades familiares. Solo se recoge diferenciadamente la presencia de niños-niñas o adultos (Beaumont y Sterry, 2005). En 2017 se aborda la fase teórica y se realiza un primer encuentro en la galería ( $\mathrm{G}$ 0) con niños de Educación infantil y Primaria -3 a 12 años. Asistieron 11 niños y 8 adultos: 19 personas en total. En la segunda fase (curso 2018-2019) se realiza la implantación del proyecto, con seis visitas a siete galerías, que arrojan unas cifras de niños-as/adultos de (G1) 10/12, (G2) 8/5, (G3) 5/4, (G4) 21/11, (G5) 24/26, (G6-7) 7/6. Se dan cita 139 personas en total. En la actualidad se empieza una fase de consolidación de la experiencia, verificación/medición de los resultados y reflexión sobre su calado y alcance.

La metodología seguida se fundamenta en la "Investigación Educativa Basada en las Artes" (Arts Based Educational Research. ABER) o también llamada "ArteInvestigación Educativa". El término, acuñado por Marín (2005:223-274, Marín y Roldán, 2017), en estrecha relación con las investigaciones de Eisner, aborda temas sobre la Educación Artística, indagaciones en el dominio de las artes visuales, etc. Este tipo de investigación comprende interrelaciones entre las personas, tanto individual como colectivamente, y las construcciones las artísticas.

Se trata de un terreno interdisciplinar que combina métodos y técnicas de investigación de otros campos. Por su naturaleza admite métodos, enfoques o instrumentos de investigación variados. En el estadio inicial del proyecto, se conforman un registro cuantificable de datos y de reflexiones en las que prima lo cualitativo. Las técnicas de sondeo van dependiendo del aspecto a valorar; lo que da lugar a combinaciones de paradigmas. Los datos evaluados de cuestionarios se combinan con entrevistas semi-estructuradas abiertas (Marín y Roldán, 2017: 18). Así, para la recogida de datos, aunque nos basamos en la medición de parámetros que aportan resultados con 
respecto al colectivo participante, se contemplan aspectos cualitativos en relación a la experiencia (modificación de percepción de los participantes después del acompañamiento). El paradigma positivista relaciona los resultados cuantificables, para descubrir regularidades y formular generalizaciones, como corresponde a la metodología cuantitativa. Predomina la investigación descriptiva o exploratoria, de corte cualitativo, orientada a identificar y describir características o fenómenos para generar conocimiento en la tendencia de investigación-acción (Bisquerra Alzina, 2009).

\section{Plan de trabajo para el acompañamiento}

El diseño del plan de trabajo del proyecto se resume en las siguientes tareas (Roselló, 2007):

- Contexto: investigación de la presencia de otras instituciones con finalidades similares y análisis de circunstancias específicas.

- Clasificación de espacios expositivos: de los 17 espacios expositivos en el área metropolitana solo 9 están incluidas en la asociación de galeristas colaboradora.

- Cronología de encuentros: viene determinada por apreciaciones con respecto a las temáticas (Sekules, 2007).

- Disposición de las galerías y concreción de la colaboración: firma del acuerdo marco entre la dirección de CEU Sevilla y la presidenta de AGAS, y firma específica con cada galería. Se establece fecha de la actividad. Se tienen en cuenta medidas de seguridad infantil e integridad de las obras expuestas.

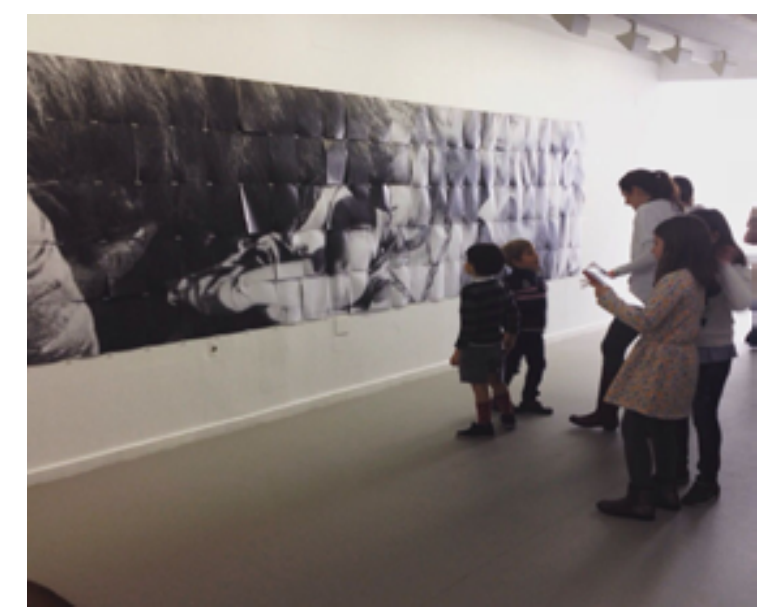

Figura 3. Niños y niñas y becarios discuten sobre la obra cambiante, 2018. (Galería Alarcón-Criado, Sevilla). Fuente propia.

- Personal vinculado: para un funcionamiento óptimo se requerían 4 alumnos/as becarios. En 2017-2018 se cuenta con una becaria y dos alumnas internas; en 2018-2019 con una becaria y una alumna interna.

- Carga de trabajo: se estiman unas 2.5-3 horas/semana/becaria. Las entrevistas de seguimiento profesorado-becarios son quincenales. El profesorado se reúne mensualmente, para revisiones. 
- Sistematización de la información: documentación compartida en Drive Office 365.

- Definición del formato de difusión: se concreta un formato de invitación que anuncia la actividad en colaboración de ambas entidades. Se editan banner y flyer publicitarios.

- Difusión del encuentro: las entidades se comprometen a difundir el acompañamiento por canales informativos.

- Presencia del artista: a ser posible se establece contacto. Se considera primordial.

- Control de asistentes. La galería y CEU Sevilla facilitan contacto por mail/móvil para confirmación de asistencia.

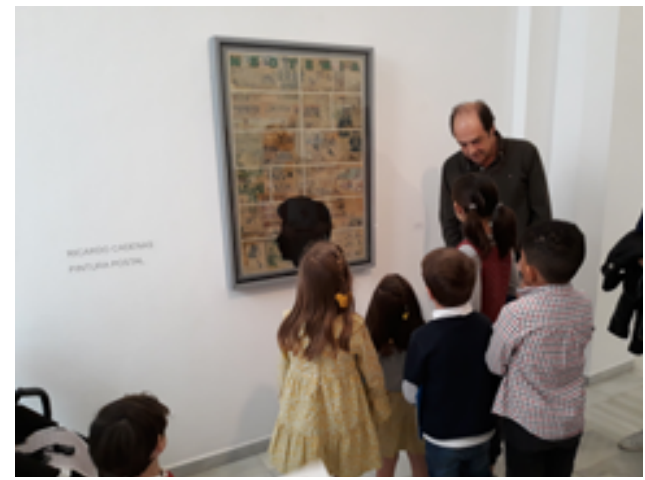

Figura 4. El artista Ricardo Cadenas comparte su obra con los niños y niñas, 2019. (Galería La Caja China, Sevilla). Fuente: propia.

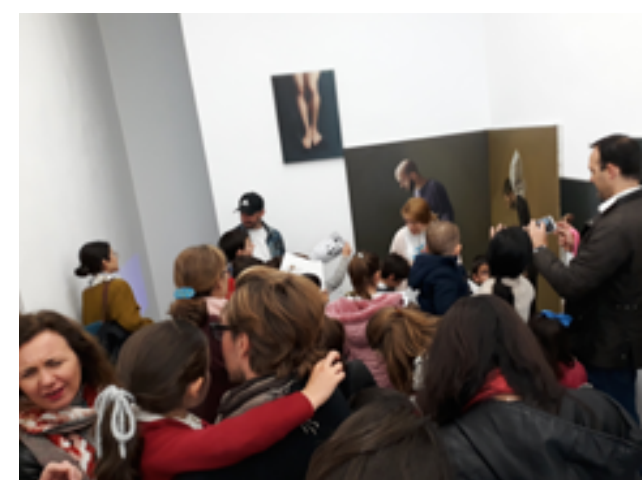

Figura 5. Niños, becarios y padres conversan ante las obras, 2019. (Galería Espacio Olvera, Sevilla). Fuente: propia.

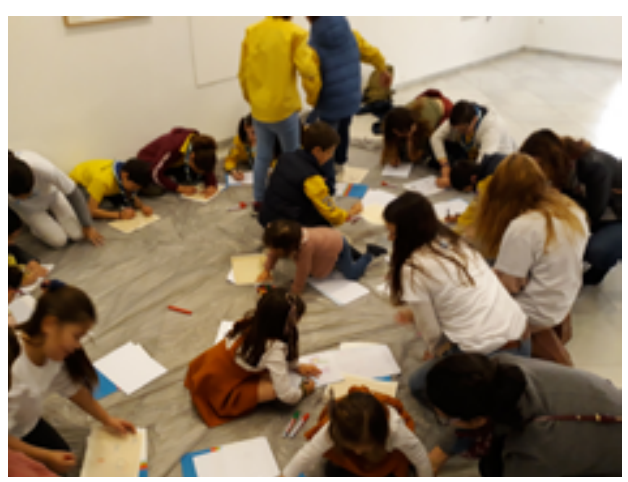

Figura 6. Grupo de niños y niñas, 2019. (Galería Rafael Ortiz, Sevilla). Fuente: propia. 


\section{Resultados}

El estudio revela cuestiones de vital importancia: la falta de referencias bibliográficas de experiencias similares, y las evidentes diferencias entre museos y galerías. El primero es un espacio en el que no se pretende un fin lucrativo, gran parte de la obra a mostrar permanece y un pequeño porcentaje cambia; mientras que en las galerías se persigue el fin lucrativo y el fluir de obras y artistas es continuo (Beaumont y Sterry, 2005). En las webs de galerías de Madrid, Barcelona y Valencia se pone de manifiesto la falta de alusión, invitaciones o programaciones infantiles. En esta línea de investigación, en la ciudad de referencia, se constata a través de las encuestas/conversaciones que; aunque son visitadas por grupos de colegios (GI-GP), de Secundaria (ES), Bachiller (B) o Bellas artes (U), ninguna insertaba esta información en su web.

\begin{tabular}{|l|c|c|c|c|c|c|}
\hline & Galería 1 & Galería 2 & Galería 3 & Galería 4 & Galería 5 & Galerías 6-7 \\
\hline Acoge Gl-GP-ES-B-U & sí & sí & sí & sí & sí & sí \\
\hline Inserta info en web & sí & no & no & no & no & no \\
\hline
\end{tabular}

Tabla 1. Datos sobre la acogida a visitas educativas y referencias de esta información en web. Fuente: propia.

En los 6 encuentros de muestra concurren 36 unidades familiares, 67 niños y 64 adultos, arrojando el total de 139 personas. Las edades de los niños están entre 2 y 11 años. (No se estima relevante las edades de los adultos.)

Los datos numéricos referidos a la hipótesis pretendida, "crear sinergias entre familias y galerías, determinando las pautas necesarias para llevar a cabo una labor social y proyecto cultural encaminado a la conquista progresiva de este espacio de arte", necesitan de las apreciaciones cualitativas para su comprensión.

\begin{tabular}{|l|c|c|c|c|c|c|c|}
\hline ASISTENCIA & Galería 1 & Galería 2 & Galería 3 & Galería 4 & Galería 5 & Galerías 6-7 & TOTAL \\
\hline Edades niños/as & $2-8$ & $5-9$ & $2.5-7$ & $3-11$ & $2-11$ & $3-9$ & $2-11$ \\
\hline Número de niños/as & 10 & 8 & 5 & 21 & 24 & 7 & 75 \\
\hline Número de adultos & 12 & 5 & 4 & 11 & 26 & 6 & 64 \\
\hline $\begin{array}{l}\text { Unidades/ } \\
\text { familias }\end{array}$ & 7 & 3 & 3 & 5 & 15 & 3 & 36 \\
\hline $\begin{array}{l}\text { U/Familias que } \\
\text { repiten }\end{array}$ & 0 & 0 & 1 & 1 & 2 & 1 & 2 \\
\hline
\end{tabular}

Tabla 2. Referencias globales sobre asistentes a los acompañamientos. Fuente: propia.

Los objetivos marcados giran alrededor de cómo y qué afecta a los participantes. Desde el encuentro piloto (Lobato y Salazar, 2017) las entrevistas semi-estructuradas evidencian la acogida positiva. La progresiva implantación del proyecto ha manifestado los factores que inciden en la consecución de los objetivos:

La capacidad para difundir la invitación a la actividad a través de distintos canales y medios es decisiva. Para facilitar la difusión de las fechas de la actividad de acompañamiento, la or-ganización del proyecto $(\mathrm{P})$ ha realizado una lista de distribución de WhatsApp con las familias que se van uniendo; estas, a su vez, hacen reenvíos. 


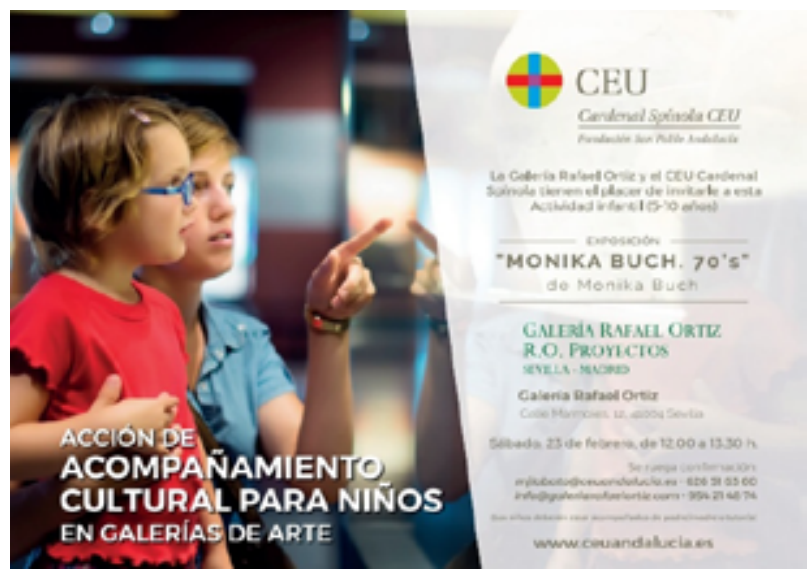

Figura 7. Imagen publicitaria de los acompañamientos, 2018. (Galería Rafael Ortiz, Sevilla) Fuente: Servicio de Producción Digital. Fundación San Pablo Andalucía CEU.

Con ocasión de la máxima asistencia, 50 personas en la galería $(\mathrm{G}) 5$, el medio de difusión de mayor eficacia ha sido el envío de mails a las AMPA, seguido de la respuesta en la lista de distribución de WhatsApp, ambas por parte de la organización de proyecto; por parte de la galería, se hacer a través de mensajes a sus contactos también a través de WhatsApp. Le sigue en número de afluencia la galería (G) 4, con 32 asistentes; en la que también la organización del proyecto (P) realiza el envío de mensajes a la lista de distribución de WhatsApp. La galería envía mensajes a sus contactos por este mismo medio.

La concurrencia queda determinada por el poder de convocatoria, de la institución y la galería, y de sus respectivas habilidades para la difusión y atracción de los destinatarios.

\begin{tabular}{|l|c|c|c|c|c|c|}
\hline & G 1 & G 2 & G 3 & G 4 & G 5 & G 6-7 \\
\hline G- Difusíón por flier & sí & sí & sí & no & no & no \\
\hline G- Difusíón AMPA & no & no & no & no & no & no \\
\hline G-Difusíón WhatsApp & no & no & no & sí & sí & sí \\
\hline G-Difusíón Twitter & sí & no & no & no & no & no \\
\hline \multicolumn{7}{|l|}{} \\
\hline P-Difusíón por flier & sí & sí & sí & no & no & no \\
\hline P-Difusíón AMPA & no & no & no & sí & sí & sí \\
\hline P-Difusíón WhatsApp & sí & sí & sí & sí & sí & sí \\
\hline P-Difusíón Twitter & sí & sí & sí & sí & sí & sí \\
\hline
\end{tabular}

Tabla 3. Evolución en los canales y medios de difusión de las invitaciones. Fuente: propia.

- La capacidad espacial de la galería es determinante: las galerías 2 y 3 se vieron influidas no solo por la falta de difusión, sino por su propia cabida. (En el caso 3, el espacio se reduce a unos quince metros cuadrados.)

- El horario de realización. Por conveniencia de los concurrentes se modifica el comienzo a las 12.00 de la mañana, lo que hace aumentar la asistencia en algunos casos. 
- Otros factores como eventos, fiestas en el calendario, distancias, climatología, etc. disminuyen la afluencia (Beaumont y Sterry, 2005).

\begin{tabular}{|l|c|c|c|c|c|c|}
\hline & G 1 & G 2 & G 3 & G 4 & G 5 & G 6-7 \\
\hline Horario de inicio & 11.00 & 11.00 & 11.00 & 12.00 & 12.00 & 12.00 \\
\hline Fecha & 20.11 .18 & 15.12 .18 & 16.02 .19 & 23.02 .19 & 06.04 .19 & 27.04 .19 \\
\hline
\end{tabular}

Tabla 4. Horario y fechas de celebración de los acompañamientos del proyecto. Fuente propia.

También se consideran resultados el instrumento de medición, previo a las entrevistas semiestructuradas. En tablas simplificadas se insertan ítems de valoración, de más bajo o menor índice (1), a más alto o mejor (5). Así, se cuantifica la afluencia en cada sesión y los factores que determinan el incremento o disminución de asistentes a los acompañamientos. En el estudio de los datos de los acompañamientos se tratan, a priori y a posteriori, la predisposición/ motivación, la satisfacción y el cumplimiento de las expectativas y el interés por repetir la experiencia (Beaumont y Sterry, 2005) de niños, niñas, adultos, becarios y galeristas.

Se recogerá la reincidencia y frecuencia con que la familia responde a las convocatorias, si ha difundido la actividad, etc. Por otro lado, cualitativamente, pretende recoger las apreciaciones subjetivas de los destinatarios a raíz de estas actividades.

\section{Discusión}

Objetivos intrínsecos del proyecto de acompañamiento son conocer y reflexionar en u n a nálisis comparativo sobre prácticas similares en galerías de otras ciudades. En ausencia de específicos estudios, sí se revisan aquellos que refieren prácticas indistintas en galerías y museos. Beaumont y Sterry (2005) analizaron encuentros familiares en ambos lugares, no la respuesta a un programa educativo.

Desde el inicio del proyecto se ponen de manifiesto las diferencias entre museos y galerías $y$, aunque se revisan estudios que consideran como positivas el fluir de obras y artistas y la concreción temática y espacial de la galería (Beaumont y Sterry, 2005), el proceso de documentación revela carencias en todos los sentidos. Se hace notar la ausencia de publicaciones con datos sobre estas actividades, y por otro lado, en las webs de las galerías. Esta circunstancia trae acarreada también ausencia de recursos materiales y pedagógicos destinados a ello. Sin embargo, este espacio de arte podría pasar a ser práctica cultural cotidiana (cfr. Calaf y Fontal, 2004:87) que favorece la colaboración inter-generacional para reforzar los vínculos entre niños, niñas y adultos.

Las encuestas semi-estructuradas a las familias alertan del efecto disuasorio. La carencia de información hace evidente también la ausencia de efecto llamada. Las familias manifiestan una percepción de sancta sanctorum, que supone una especie de auto-veto a traspasar su umbral. No se trata de que las galerías puedan estar cerradas a las familias; aunque es evidente que ninguna galería hace alusión a qué tipo de público puede atravesar sus puertas, se pone de manifiesto la usencia de invitación a la creación de un imaginario propio (Gómez y Vaquero-Cañestro, 2014). 
Hemos encontrado resonancias similares en la pretensión de propiciar encuentros, narraciones visuales compartidas y en la transmisión del sentido de pertenencia. El concepto de suprimir fronteras y límites resitúa la galería como una referencia en su entorno para ofrecer vías a la comunicación familiar (Gómez y Vaquero-Cañestro, 2014:389).

A través de las conversaciones con los coordinadores de estos espacios se arguye que las galerías son visitadas por colegios, universitarios, etc. con sus planteamientos didácticos correspondientes. Este dista mucho de lo usual en los museos (Calaf y Fontal, 2004). Del mismo modo, el museo recoge en sus páginas web la posibilidad de todo tipo de actividades de las que las galerías carecen o no hacen eco.

\section{Conclusión}

El proyecto resulta relevante porque ejemplifica una forma de encuentro de los becarios con el arte y la sociedad en el marco del ApS, generando una dinámica de participación muy significativa para su formación como futuro docente, evidenciada en sus manifestaciones de las encuestas semi-estructuradas.

Cualquier proyecto cultural debe adaptarse al público que pretender captar y controlar los factores que afectan a la consecución de los objetivos. La descripción de la actividad en sí misma facilita una implantación extrapolable. Este estudio arroja datos para conocer la estructura básica necesaria con el objeto de llevar a cabo experiencias similares. En él se hace alusión al control de factores de vital importancia, como la red de difusión de las convocatorias, recurriendo a medios como AMPAs, listas de distribución de mail, WhatsApp, Twitter, etc. Reflexionamos sobre los aspectos que servirán para dar apoyo a otros proyectos de ApS que se deseen implementar; puesto que la capacidad espacial de la galería, la climatología, el horario, eventos o fiestas paralelas también afectan, positiva o negativamente al ritmo de las familias. La conquista del espacio, el sentido de pertenencia, "vivir en el arte" no consigue con solo algunas visitas.

Actualmente, en la fase de implantación, destacamos los resultados obtenidos una vez iniciados los encuentros, en el primer curso académico destinado a llevar a cabo los acompañamientos. En relación con el macro-objetivo general, "crear sinergias entre familias y galerías", en tanto que se trata de maximizar, sumar, las cualidades de cada uno de los elementos, porque una aprende de la otra, los resultados han sido muy positivos. Un grupo de casi 140 personas se ha involucrado en los acompañamientos. Sin embargo, el proyecto vincula su éxito, no solo al número creciente de asistentes, sino a iniciar a los participantes en prácticas familiares y sociales que, de forma autónoma, revelen posibles identidades y narrativas personales vinculadas a los encuentros con el arte en las galerías, e interiorizados como otros rituales culturales compartidos.

La concurrencia quedará determinada por el poder de convocatoria, tanto de la institución como de la galería, y de sus respectivas habilidades para implementar canales de difusión con poder de atracción para los destinatarios elegidos.

La concreción de una reunión de intereses ha conseguido la generación de sinergias en iniciativas culturales comunes; se han establecido relaciones y aunado voluntades entre las gale- 
rías, el profesorado-investigadores, alumnos de grado y familias.

Sin embargo, la repercusión concreta de la experiencia se podrá valorar al realizar el análisis estadístico; para el que de momento no hay datos suficientes, sobre el grupo participante y los resultados del análisis, puesto que se llevan realizadas seis acciones de acompañamiento. Se estima necesario el desarrollo del proyecto en dos a tres años para verificar el calado de la propuesta en la sociedad.

\section{Referencias bibliográficas}

Alsina, P., y Giráldez, A. (Coords.) (2012). La competencia cultural y artística, 7 ideas clave. (1 ${ }^{\text {a }}$ ed.). Barcelona: Graó.

Beaumont, E., y Sterry P. (2005). A study of grandparents and grandchildren as visitors to museus and art galleries in the UK. Museum and society, 3(3), 167-180. University of Leicester. Recuperado de: https://journals.le.ac.uk/ojs1/index.php/mas/article/view/68/85

Benjamin, W. (2003). La obra de arte en la época de su reproductibilidad. (1 $1^{\text {a }}$ ed.). México, D.F., México: Ítaca.

Bisquerra Alzina, R. (Coord.). (2009). Metodología en investigación educativa. (1 ${ }^{\text {a }}$ ed.). Madrid: E. La Muralla.

Borja-Villel y Equipo Educativo del museo (2018). Programación educativa del Museo Nacional Centro de Arte Reina Sofía. Recuperado de: http://www.museoreinasofia.es/sites/

default/files/banner/descargas/programa_educativo_reina_sofia_2018-19.pdf

Bourdieu, P. (1983) Los tres estados del capital cultural. Recuperado de: http://sociologiac.net/ biblio/Bourdieu-LosTresEstadosdelCapitalCultural.pdf.

Calaf, R., y Fontal, O. (Coords.) (2004). Comunicación educativa del patrimonio: referentes, modelos y ejemplos ( $1^{\mathrm{a}}$ ed.). Gijón: Trea.

Calaf, R., y Fontal, O. (2010). Cómo enseñar arte en la escuela (1 ${ }^{\mathrm{a}}$ ed.). Madrid: Síntesis.

Centro de Cultura Tradicional Museo Escolar de Pusol. Recuperado de: https://www.museopusol. com/media/descargas/plan-voluntariado.pdf

Federación Española de Amigos de los Museos. Recuperado de: https://plataformavoluntariado. org/wp-content/uploads/2018/10/amigos-museos-y-voluntariado-cultural.pdf

Fontal Merillas, O., Marín Cepeda, S., y García Ceballos, S. (2015). Educación de las artes visuales y plásticas en Educación Primaria (1 ${ }^{\text {a }}$ ed.). Madrid: E. Paraninfo.

Gómez del Águila, L.M., y Vaquero-Cañestro, C. (2014). Educación Artística y experiencia importada: Cuando la construcción de significados recae en lo anecdótico. Arte, Individuo y Sociedad, 26(3), 387-400. https://doi.org/10.5209/rev_ARIS.2014.v26.n3.42543

Huerta, R., y De la Calle, R. (2007). Espacios estimulantes: Museos y educación artística (1 $1^{\mathrm{a}}$ ed.). Valencia: Universidad de Valencia.

IES Miguel Catalán (12 de mayo 2016). Nuestros nietos de la ESO nos llevan al Museo Arqueológico Nacional. Recuperado de: http://clasicasmiguelcatalan.blogspot.com/2016/05/nuestrosnietos-de-la-eso-nos-llevan-al.html 
Laboratorio Permanente de Público de Museos (2012). Conociendo a todos los públicos. ¿Qué imágenes se asocian a los museos? Madrid, España: Secretaría General Técnica. Centro de Publicaciones. Ministerio de Educación, Cultura y Deporte.

Lobato Suero, Ma J., y Salazar Pera, C. (2017). Acción de acompañamiento cultural para niños en centros y galerías de arte. En Antonio Bernal-Guerrero (Coord.), Simposio internacional el desafío de emprender en la escuela del siglo XXI. 56-68. Sevilla: Departamento de Teoría e Historia de la Educación y Pedagogía Social de la Universidad de Sevilla.

Marín Viadel, R. (2005). La investigación educativa basada en las artes visuales o "ArteInvestigación educativa”. En R. Marín Viadel (2005). Investigación en educación artística. (1 $1^{\text {a }}$ ed. pp. 223274). Granada: Universidad de Granada y Universidad de Sevilla.

Marín Viadel, R., y Roldán, J. (2017). Ideas Visuales. Investigación Basada en Artes e investigación artística. (1 ${ }^{\mathrm{a}} \mathrm{ed}$.). Granada: Universidad de Granada.

Martínez, M. (Ed.) (2008). Aprendizaje servicio y responsabilidad social en las universidades (1 ${ }^{\mathrm{a}}$ ed.). Barcelona, España: Octaedro.

Moreno González, A. (2016). La mediación artística: arte para la transformación social, la inclusión social y el desarrollo comunitario. ( $1^{\text {a }}$ ed.). Barcelona: Octaedro.

Muntadas A. Máster en Arte: Idea y Producción. 22 de Abril, 2019. Recuperado de: https:// bellasartes.us.es/destacamos/antoni-muntadas-en-el-master-en-arte-idea-y-produccion22-de-abril-de-2019

Museo Arqueológico Nacional. (sin fecha). Voluntarios Culturales de la tercera edad para enseñar los Museos de España a niños, jóvenes y jubilados. Recuperado de: http://www.man.es/ $\mathrm{man} / \mathrm{museo} /$ voluntariado-cultural.html

Orden ECI/3960/2007, de 19 de diciembre, por la que se establece el currículo y se regula la ordenación de la Educación Infantil. Ministerio de Educación y Ciencia. «BOE» núm. 5, de 5 de enero de 2008. Recuperado de: https://www.boe.es/buscar/pdf/2008/BOE-A-2008222-consolidado.pdf

Ortega, I., y Pardo, D. (2017). La educación galerística como campo emergente de la educación artística en contextos no formales. Revista Arte, Individuo y Sociedad, 29(3), 501-517.

PLOM Gallery. Galería de arte para niños. Recuperado de: https://www.plomgallery.com/

Real Decreto 126/2014, de 28 de febrero, por el que se establece el currículo básico de la Educación Primaria. Ministerio de Educación, Cultura y Deporte «BOE» núm. 52, de 1 de marzo de 2014. Recuperado de: https://www.boe.es/buscar/pdf/2014/BOE-A-2014-2222consolidado.pdf

Roselló Cerezuela, D. (2007). Diseño y evaluación de proyectos culturales (4 ${ }^{\mathrm{a}}$ ed.). Barcelona: Ariel Patrimonio.

San Millán, B. y Barrenetxea, J. (2012) Narratividad situada. Reflexión sobre la experiencia "Historias construidas" (exposición infantil en el Centro de Arte Contemporáneo Huarte) Recuperado de: https://www.youtube.com/watch?v=E-RXtHVjTxM

Sánchez-Pacheco, S. (2011). Arte yeducación en museos y centros culturales, 25-7-2011. Recuperado de: http://ubuntucultural.com/arte-y-educacion-en-museos-y-centros-culturales-2/ 
Sekules, V. (2007). Comportamiento bueno y malo: educación y arte contemporáneo en el Museo de arte. En R. Huerta, R. y R. de la Calle (Eds.), Espacios estimulantes: Museos y educación artística ( $1^{\mathrm{a}}$ ed, pp. 45-54). Valencia: Universidad de Valencia.

Vallejo Delgado, C. (2003). En arte como en ciencia. Una defensa de la interdisciplinariedad. En J. C. Arañó y A. Mañero (Eds.), Actas Congreso INARS: la investigación en las artes plásticas y visuales. Sevilla: Universidad de Sevilla (Secretariado de publicaciones).

Vicente, Á. (2013). La galería compite con el museo. Recuperado de: https://elpais.com/cultura/2013/11/28/actualidad/1385669744_309030.html

Zorrilla Silvestre, L., Capella Peris, C., y Gil Gómez, J. (2016). Aprendizaje-servicio. En O. Chiva Bartoll y M. Martí Puig (Coords.), Métodos pedagógicos activos y globalizadores. Conceptualización y propuestas de aplicación. (1ª ed. pp. 67-83). Barcelona: Graó. 